\title{
Why tocilizumab could be an effective treatment for severe COVID-19?
}

\author{
Binqing $\mathrm{Fu}^{1,2,3}$, Xiaoling $\mathrm{Xu}^{3}$ and Haiming Wei ${ }^{1,2,3^{*}}$ (])
}

\begin{abstract}
A severe pneumonia-associated respiratory syndrome caused by a new coronavirus was identified in December 2019 (COVID-19), spread rapidly and has become a world-wide public health challenge. About 25\% of COVID-19 patients experienced severe complications including acute respiratory distress syndrome (ARDS), and even progressed into an intensive care unit (ICU) admission and died. The exploration for the mortality causes and advancing novel therapeutic development of severe COVID-19 is crucial at the moment. The biopsy samples analysis at autopsy suggested that increased alveolar exudate caused by aberrant host immune response and inflammatory cytokine storm probably impedes alveolar gas exchange and contributes to the high mortality of severe COVID-19 patients. Our research has identified that pathogenic $T$ cells and inflammatory monocytes incite inflammatory storm with large amount of interleukin 6, therefore monoclonal antibody that targets the IL-6 pathways may potentially curb inflammatory storm. Moreover, Tocilizumab treatment that blocking IL-6 receptors showed inspiring clinical results including temperature returned to normal quickly and respiratory function improved. Therefore, we suggest that Tocilizumab is an effective treatment in severe patients of COVID-19 to calm the inflammatory storm and reduce mortality.
\end{abstract}

Keywords: COVID-19, SARS-CoV-2, Acute respiratory distress syndrome (ARDS), Inflammatory storm, IL-6, Tocilizumab

\section{Introduction}

In the past decades, two known pathogenic human coronaviruses, severe acute respiratory syndrome $\mathrm{CoV}$ (SARS-CoV) and Middle East respiratory syndrome $\mathrm{CoV}$ (MERS-CoV), have been reported to damage the respiratory tract and cause high morbidity and mortality [1]. Severe acute respiratory syndrome coronavirus 2 (SARS-CoV-2) is a newly discovered coronavirus, was reported at December $2019(2019-\mathrm{nCoV})$ in the city Wuhan, Hubei province, China [2]. Up to 21th of March 2020, 81,416 cases have been reported with 3261 fatal cases according to the Chinese Center for Disease Control and Prevention (CDC). Meanwhile, 190,000 cases

\footnotetext{
*Correspondence: ustcwhm@ustc.edu.cn

${ }^{1}$ Institute of Immunology and the CAS Key Laboratory of Innate Immunity and Chronic Disease, School of Life Science and Medical Center, University of Science and Technology of China, Hefei, Anhui 230001, China

Full list of author information is available at the end of the article
}

have been reported with 7992 fatal cases in other countries except China. In Italy, to date there are about 47.021 infected and 4.032 deaths [3]. A global outbreak of the SARS-CoV-2 caused Corona Virus Disease (COVID-19) seems inevitable. Among these COVID-19 patients, most of them have the common symptoms including fever, cough, and myalgia or fatigue at onset. The majority of patients can recover, however, about $25 \%$ of patients will progress into severe complications including acute respiratory distress syndrome (ARDS), which may worsen rapidly into respiratory failure, need an intensive care unit (ICU) and even cause multiple organ failure [4, 5]. Therefore, the exploration for the mortality causes and advancing novel therapeutic development of severe COVID-19 is crucially important at the moment.

\section{What is the crucial cause for mortality in COVID-19?}

Although virus-induced cytopathic effects and viral evasion of host immune responses are believed to be important in disease severity, studies from humans who died

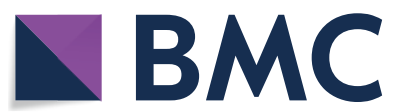

(c) The Author(s) 2020. This article is licensed under a Creative Commons Attribution 4.0 International License, which permits use, sharing, adaptation, distribution and reproduction in any medium or format, as long as you give appropriate credit to the original author(s) and the source, provide a link to the Creative Commons licence, and indicate if changes were made. The images or other third party material in this article are included in the article's Creative Commons licence, unless indicated otherwise in a credit line to the material. If material is not included in the article's Creative Commons licence and your intended use is not permitted by statutory regulation or exceeds the permitted use, you will need to obtain permission directly from the copyright holder. To view a copy of this licence, visit http://creativecommons.org/licenses/by/4.0/. The Creative Commons Public Domain Dedication waiver (http://creativecommons.org/publicdomain/zero/1.0/) applies to the data made available in this article, unless otherwise stated in a credit line to the data. 
of SARS and MERS suggested that an aberrant host immune response resulting in an inflammatory cytokine storm and lethal disease [1]. Similar to the inflammatory cytokines in SARS and MERS, patients with COVID-19 also have increased plasma concentrations of inflammatory cytokines, such as tumour necrosis factor $\alpha$ (TNF$\alpha$ ),interleukins (IL) 2,7 , and 10 , granulocyte-colony stimulating factor (G-CSF), monocyte chemoattractant protein 1 , macrophage inflammatory protein 1 alpha, and interferon- $\gamma$-inducible protein 10 , especially in ICU patients, which implied a cytokine storm occurred [4].

Moreover, COVID-19 patients have decreased lymphocytes in peripheral blood and characteristic pulmonary ground glass changes on imaging $[4,5]$. Most importantly, in the biopsy samples at autopsy from patients who died from COVID-19, histological examination showed bilateral diffuse alveolar damage including edema, proteinaceous exudate, focal reactive hyperplasia of pneumocytes with patchy inflammatory cellular infiltration, and multinucleated giant cells [6, 7]. It also has been recovered from autopsy examination that Type II alveolar epithelial cells proliferate markedly, with some cells exfoliated. The alveolar septum is hyperemic, edematous, with clear intravascular thrombosis. Focal monocytes, lymphocytes and plasma cells are infiltrating into pulmonary interstitium. Immunohistochemistry results showed positive for immunity cells including CD3, CD4, CD8, CD20, CD79a, CD5, CD38 and CD68 [8]. These phenomena further suggest severe pulmonary inflammatory immune cells exist in SARS-CoV-2 infection. Therefore, increased alveolar exudate caused by aberrant host immune response and inflammatory cytokine storm probably impedes alveolar gas exchange and contributes to the high mortality of severe COVID-19 patients.

\section{IL-6 is a potential blocking target to calm inflammatory storm}

Inflammatory storm refers to an excessive inflammatory response flaring out of control and the immune system gone awry. To identify which kind of immune cells are involved in and which inflammatory cytokine is the critical target in these severe COVID-19 patients, we analyzed peripheral blood samples from patients with severe or critical COVID-19 from The First Affiliated Hospital of University of Science and Technology of China and observed monocytes and $\mathrm{T}$ cells from severe or critical COVID-19 patients decreased significantly compared to normal controls. These aberrant pathogenic $\mathrm{T}$ cells from critical ICU care COVID-19 patients showed activated characteristic accompanied with co-expressing IFN- $\gamma$ and GM-CSF. This phenomenon aroused our alarm, for GM-CSF has the capability to control diverse pathogenic capabilities of inflammatory myeloid cells, especially monocytes [9]. As expected, inflammatory monocyte with $\mathrm{CD} 14^{+} \mathrm{CD} 16^{+}$phenotype exists in peripheral blood of COVID-19 patients and has larger population in critical COVID-19 patients from ICU. Note that without any re-stimulation with PMA or incubation with monensin, large amount of IL- 6 could be tested from these inflammatory monocytes especially in ICU patients. Therefore, these pathogenic Th1 cells $\left(\mathrm{GM}-\mathrm{CSF}^{+} \mathrm{IFN}-\gamma^{+}\right)$ and inflammatory monocytes $\left(\mathrm{CD} 14^{+} \mathrm{CD} 16^{+}\right.$with high expression of IL-6) exist especially in critical ICU COVID-19 patients [10]. Given that large amount of mononuclear inflammatory lymphocytes have been observed in the biopsy samples at autopsy from COVID19 patients, we believe that these pathogenic $\mathrm{T}$ cells and inflammatory monocytes may enter the pulmonary circulation in large numbers and incite inflammatory storm in severe or critical COVID-19 patients (Fig. 1).

\section{Tocilizumab treatment is effective to reduce the mortality of severe COVID-19}

Tocilizumab is the first marketed IL- 6 blocking antibody through targeting IL- 6 receptors and has proved its safety and effectiveness in therapy for rheumatoid arthritis (Fig. 2). In order to verify whether targeted IL-6, may potentially be the effective and safe way to reduce mortality of COVID-19, 21 patients diagnosed as severe or critical COVID-19 from The First Affiliated Hospital of University of Science and Technology of China and Anhui Fuyang Second People's Hospital were recruited and given tocilizumab therapy (Table 1). Patients received standard treatment according to the Diagnosis and Treatment Protocol for COVID-19 $\left(7^{\text {th }}\right.$ edition), including lopinavir, methylprednisolone, other symptom relievers and oxygen therapy. The results of tocilizumab treatment are inspiring. The temperature of all the patients returned to normal very quickly. The respiratory function and all other symptoms improved remarkably. Among these 21 patients, 20 patients have been recovered and discharged within 2 weeks after the tocilizumab therapy. One left patient is recovering and out of ICU care. No adverse drug reactions were reported during the treatment with tocilizumab [11]. With these promising preliminary clinical results, we further launched the multicenter, large-scale clinical trials (ChiCTR2000029765) and have already about 500 severe or critical patients treated this way.

The immunotherapy strategy about Tocilizumab treatment has been formally included in the diagnosis and treatment program of COVID-19 (7th edition) of the national health commission of China since 3th March 2020 as following: Tocilizumab can be used in patients with extensive bilateral lung lesions opacity or in severe or critical patients, who have elevated 


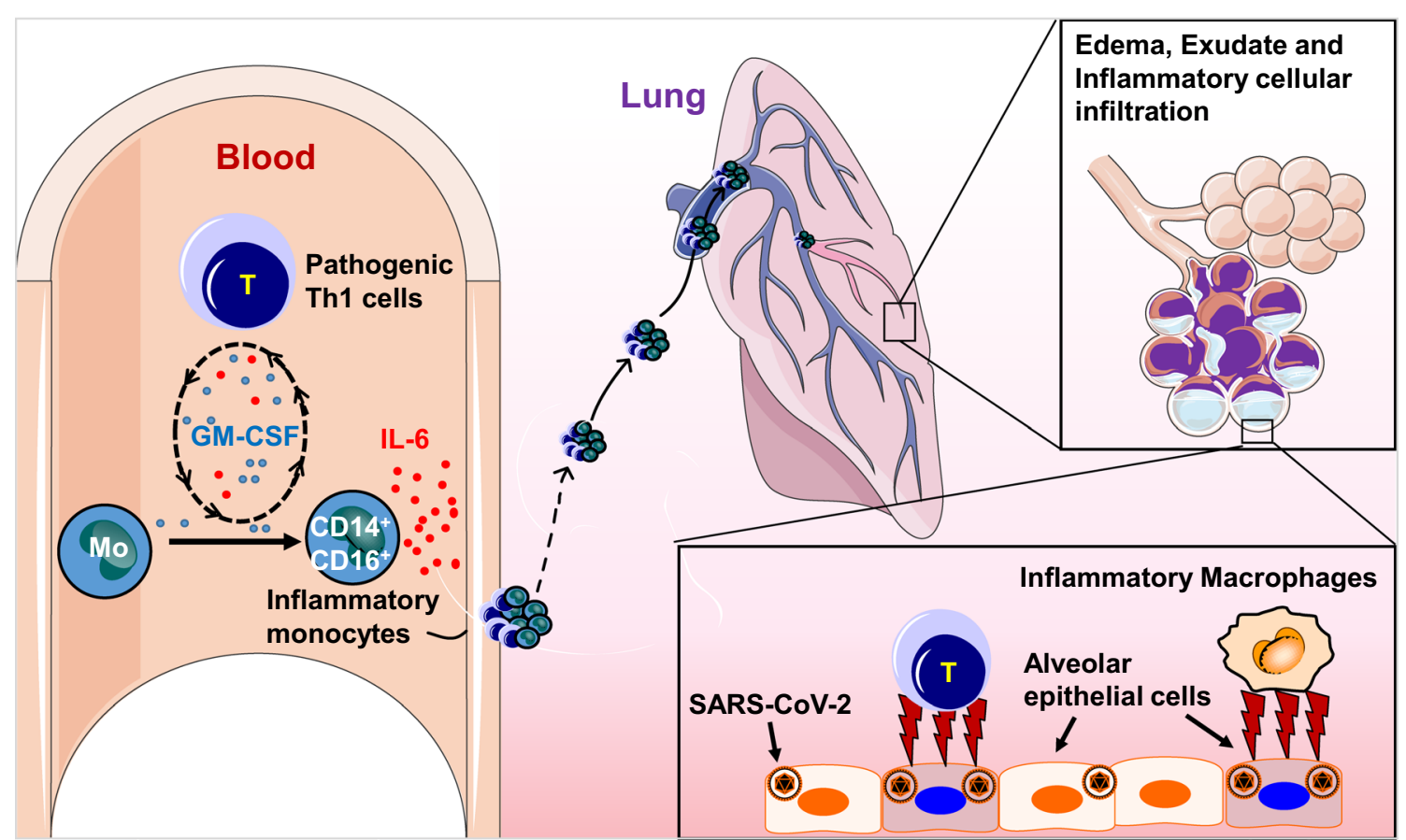

Fig. 1 Pathogenic T cells and inflammatory monocytes with high IL-6 secretion may enter the pulmonary circulation in large numbers,incite the inflammatory storm and lead an immune disorder in severe COVID-19 patients

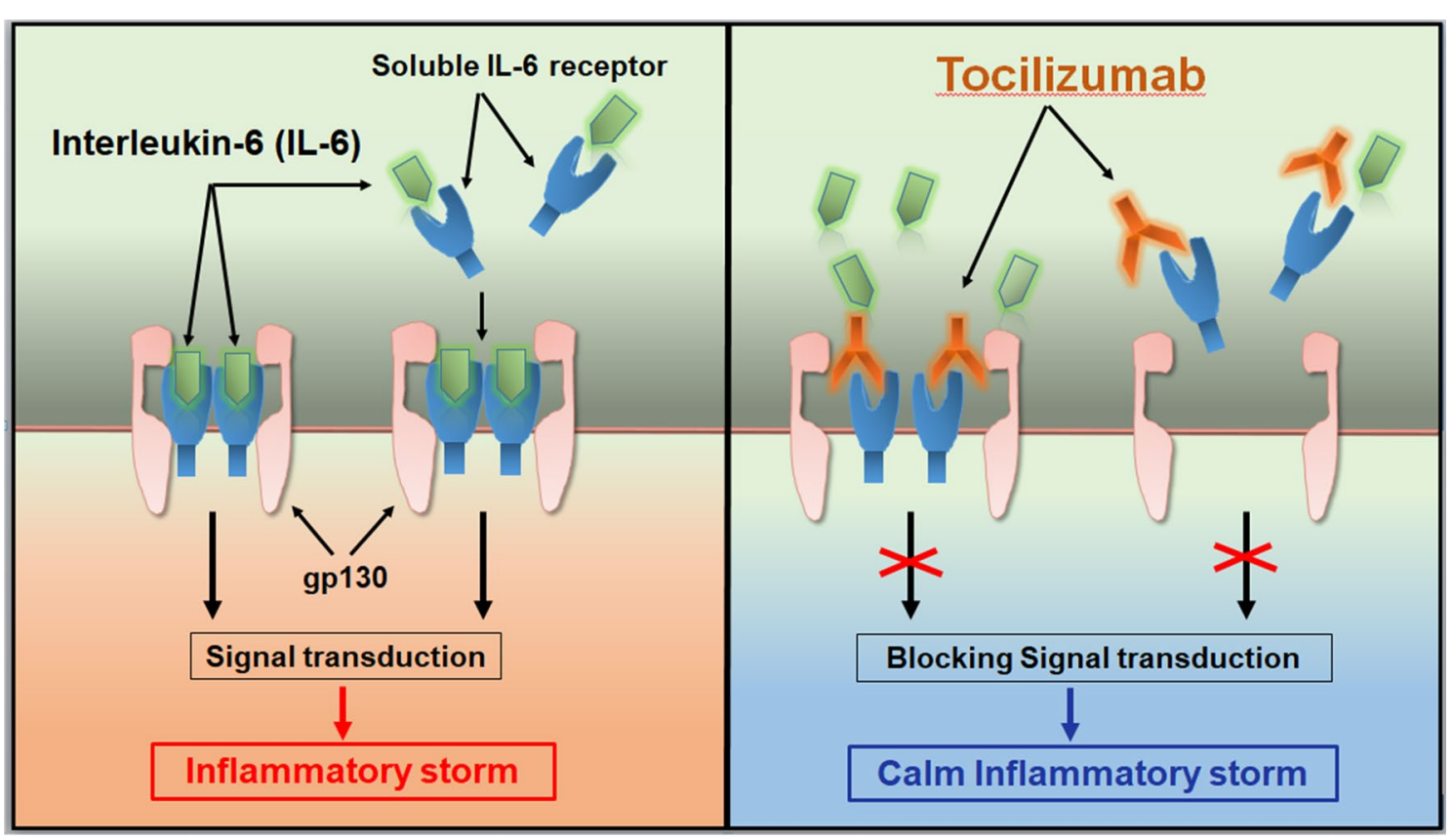

Fig. 2 Tocilizumab calms the inflammatory storm through blocking IL-6 receptors

laboratory detected IL-6 levels. The first dose is $4-8 \mathrm{mg} /$ $\mathrm{kg}$ (the recommended dose is $400 \mathrm{mg}$, diluted to $100 \mathrm{ml}$ with $0.9 \%$ normal saline, and the infusion time is more than $1 \mathrm{~h}$ ). For patients with poor initial efficacy, an additional application can be made after $12 \mathrm{~h}$ (the dose is the same as before). The maximum number of times of 
Table 1 Patients can be considered to use Tocilizumab and the exclusion criteria

\begin{tabular}{|c|c|}
\hline Patients can be considered to use Tocilizumab & Exclusion criteria \\
\hline $\begin{array}{l}\text { (1) Patients diagnosed with COVID-19 with high risk factors, severe or } \\
\text { critical patients }\end{array}$ & (1) Patients who are participating in clinical trials of other drugs \\
\hline (2) Increased concentration of IL-6 levels & (2) Pregnant or lactating women \\
\hline \multirow{7}{*}{$\begin{array}{l}\text { (3) The patient or authorized family member agrees to use Tocilizumab } \\
\text { treatment and sign the informed consent }\end{array}$} & (3) Rheumatoid immune-related diseases \\
\hline & $\begin{array}{l}\text { (4) Long-term oral medication of anti-rejection drugs or immunoregulatory } \\
\text { drugs }\end{array}$ \\
\hline & (5) Hypersensitive to Tocilizumab or any pharmaceutical excipients \\
\hline & $\begin{array}{l}\text { (6) Active pulmonary tuberculosis patients with bacterial and fungal infec- } \\
\text { tions }\end{array}$ \\
\hline & (7) Organ transplant patients \\
\hline & (8) Patients with mental disorders \\
\hline & (9) ALT/AST $>5 U L N$, neutrophil $<0.5 \times 10^{9} / \mathrm{L}$, platelet $<50 \times 10^{9} / \mathrm{L}$ \\
\hline
\end{tabular}

administration is two, and the maximum dose of a single dose should not exceed $800 \mathrm{mg}$. Note that patients with allergic reactions, such as tuberculosis and other active infection are contraindicated. We suggest that IL-6 concentrations can be detected if fever persists for more than 3 days. By chemiluminescence detection, if serum IL- 6 content is over $20 \mathrm{pg} / \mathrm{ml}$, Tocilizumab can be used. The IL- 6 will be temporarily increased in serum in the next few days, for its receptors have been blocked by Tocilizumab. Together, Tocilizumab treatment is recommended to reduce the mortality of severe COVID-19.

\section{Discussion}

All three coronaviruses, including SARS-CoV, MERS$\mathrm{CoV}$ and SARS-CoV-2, induce aberrant non-effective host immune responses that are associated with severe lung pathology. The new SARS-CoV-2 additionally causes serious alveolar mucus infiltration and multiple organ failure. As the SARS-CoV-2 continues to spread, the numbers of fatal cases rise exponentially in many countries, advancing novel therapeutic development becomes crucial to minimize the number of deaths from COVID19. In the absence of specific antiviral drugs, existing host-directed therapies could potentially be repurposed to treat COVID-19. China's plan of Tocilizumab treatment has shown its remarkable effectiveness and safety in clinical practice over the past 2 months, hoping it will benefit other countries fighting the pandemic and reduce the mortality of severe COVID-19 as well.

\section{Abbreviations}

SARS-CoV: Severe acute respiratory syndrome CoV; MERS-CoV: Middle east respiratory syndrome CoV; SARS-CoV-2: severe acute respiratory syndrome coronavirus 2 outbreak in 2019; COVID-19: The SARS-CoV-2 caused Corona Virus Disease; GM-CSF: Granulocyte-macrophage colony-stimulating factor;
IL-6: Interleukin-6; ARDS: Acute respiratory distress syndrome; ICU: Intensive care unit.

\section{Acknowledgements}

Thanks to all the members from immunology research group of Prof. Haiming Wei in University of Science and Technology of China (USTC) and clinical group of Prof. Xiaoling Xu in The First Affiliated Hospital of USTC for their contributions of this novel Tocilizumab therapeutic treatment towards COVID-19.

\section{Authors' contributions}

HW supervised the project and provided crucial ideas. XX supervised the clinical treatment of patients of 2019-CoV. B.F. wrote this manuscript with HW. All authors read and approved the final manuscript.

\section{Funding}

This work was supported by the Natural Science Foundation of China (81788101, 81922028), and Youth Innovation Promotion Association of Chinese Academy of Sciences (Grant 2019442).

\section{Availability of data and materials}

Not applicable.

\section{Ethics approval and consent to participate}

All patients had signed informed consent before using tocilizumab and agreed to publish case series. Ethical approval (No. 2020-XG (H)-005) was conducted in accordance with the international conference on Hamonisation Guidelines for good clinical practice and the Declaration of Helsinki and institutional ethics guidelines and obtained from the Ethics Committee from The First Affiliated Hospital of University of Science \& Technology of China for emerging infectious diseases.

\section{Consent for publication}

Not applicable.

\section{Competing interests}

The authors declare no competing interests.

\section{Author details}

${ }^{1}$ Institute of Immunology and the CAS Key Laboratory of Innate Immunity and Chronic Disease, School of Life Science and Medical Center, University of Science and Technology of China, Hefei, Anhui 230001, China. ${ }^{2}$ Hefei National Laboratory for Physical Sciences at Microscale, University of Science and Technology of China, Hefei, Anhui 230001, China. ${ }^{3}$ The First Affiliated Hospital of USTC, Division of Life Sciences and Medicine, University of Science and Technology of China, Hefei, Anhui 230001, China. 
Received: 16 March 2020 Accepted: 9 April 2020

Published online: 14 April 2020

\section{References}

1. Channappanavar R, Perlman S. Pathogenic human coronavirus infections: causes and consequences of cytokine storm and immunopathology. Semin Immunopathol. 2017;39:529-39.

2. Wang C, Horby PW, Hayden FG, Gao GF. A novel coronavirus outbreak of global health concern. Lancet. 2020;395(10223):470-3.

3. https://lab.gedidigital.it/gedi-visual/2020/coronavirus-i-contagi-in-italia/.

4. Huang C, Wang Y, Li X, Ren L, Zhao J, Hu Y, Zhang L, Fan G, Xu J, Gu X, et al. Clinical features of patients infected with 2019 novel coronavirus in Wuhan, China. Lancet. 2020;395(10223):497-506.

5. Wang D, Hu B, Hu C, Zhu F, Liu X, Zhang J, Wang B, Xiang H, Cheng Z, Xiong Y, et al. Clinical characteristics of 138 hospitalized patients With 2019 novel coronavirus-infected pneumonia in Wuhan, China. JAMA. 2020. https://doi.org/10.1001/jama.2020.1585.

6. Tian S, Hu W, Niu L, Liu H, Xu H, Xiao SY. Pulmonary pathology of early phase 2019 novel coronavirus (COVID-19) pneumonia in two patients with lung cancer. J Thorac Oncol. 2020. https://doi.org/10.1016/j. jtho.2020.02.010.
7. Xu Z, Shi L, Wang Y, Zhang J, Huang L, Zhang C, Liu S, Zhao P, Liu H, Zhu L, et al. Pathological findings of COVID-19 associated with acute respiratory distress syndrome. Lancet Respir Med. 2020;8(4):420-2.

8. Luo W, Yu H, Gou J, Li X, Sun Y, Li J, Liu L. Clinical pathology of critical patient with novel coronavirus pneumonia (COVID-19). Preprints 2020, 2020020407

9. Croxford AL, Lanzinger M, Hartmann FJ, Schreiner B, Mair F, Pelczar P, Clausen BE, Jung S, Greter M, Becher B. The cytokine GM-CSF drives the inflammatory signature of CCR2 + monocytes and licenses autoimmunity. Immunity. 2015;43:502-14

10. Zhou YG, Fu BQ, Zheng XH, Wang DS, Zhao CC, Qi YJ, Sun R, Tian ZG, Xu XL, Wei HM. Pathogenic T cells and inflammatory monocytes incite inflammatory storm in severe COVID-19 patients. Nat Sci Rev. 2020. https ://doi.org/10.1093/nsr/nwaa041.

11. Xu XL, Han MF, Li TT, Sun W, Wang DS, Fu BQ, Zhou YG, Zheng XH, Yang $Y$, Li XY, Zhang XH, Pan AJ, Wei HM. Effective treatment of severe COVID-19 patients with tocilizumab. ChinaXiv. 2020;202003(00026):V1.

\section{Publisher's Note}

Springer Nature remains neutral with regard to jurisdictional claims in published maps and institutional affiliations.
Ready to submit your research? Choose BMC and benefit from:

- fast, convenient online submission

- thorough peer review by experienced researchers in your field

- rapid publication on acceptance

- support for research data, including large and complex data types

- gold Open Access which fosters wider collaboration and increased citations

- maximum visibility for your research: over $100 \mathrm{M}$ website views per year

At BMC, research is always in progress.

Learn more biomedcentral.com/submissions 